\title{
EFFECT OF GRAIN SIZE AND CONTROLLED ATMOSPHERES ON THE THERMAL STABILITY OF ALUMINIUM TITANATE
}

\author{
I.M. Low and Z. Oo \\ Department of Imaging \& Applied Physics, Curtin University of Technology, GPO Box U1987, Perth, \\ WA 6845, Australia
}

\begin{abstract}
Aluminium titanate $\left(\mathrm{Al}_{2} \mathrm{TiO}_{5}\right)$ is an excellent refractory and thermal shock resistant material due to its relatively low thermal expansion coefficient and high melting point. However, $\mathrm{Al}_{2} \mathrm{TiO}_{5}$ is only thermodynamically stable above $1280^{\circ} \mathrm{C}$ and undergoes a eutectoid-like decomposition to $\alpha-\mathrm{Al}_{2} \mathrm{O}_{3}$ and $\mathrm{TiO}_{2}$ (rutile) at the temperature range of $900-1280^{\circ} \mathrm{C}$. Hitherto, the effect of grain size and atmosphere on the kinetics of decomposition is poorly understood but experimental evidences suggest a nucleation and growth controlled process. In this paper, we describe the role of grain size and controlled atmospheres on the thermal stability of $\mathrm{Al}_{2} \mathrm{TiO}_{5}$. In particular, the effects of grain size and oxygen partial pressure on the rate of isothermal decomposition of $\mathrm{Al}_{2} \mathrm{TiO}_{5}$ at $1100^{\circ} \mathrm{C}$ have been investigated. Results show that the thermal stability of $\mathrm{Al}_{2} \mathrm{TiO}_{5}$ increases as the grain size and oxygen partial pressure increases. However, both the on-set temperature nor the temperature range of $\mathrm{Al}_{2} \mathrm{TiO}_{5}$ thermal decomposition are not affected by the variation of oxygen partial pressure present in the furnace atmosphere.
\end{abstract}

KEYWORDS: Thermal stability, $\mathrm{Al}_{2} \mathrm{TiO}_{5}$, grain size, atmosphere, neutron diffraction, decomposition.

\section{INTRODUCTION}

Aluminium titanate $\left(\mathrm{Al}_{2} \mathrm{TiO}_{5}\right)$ is an excellent refractory and thermal shock resistant material due to its relatively low thermal expansion coefficient $\left(\sim 1 \times 10^{-6}{ }^{\circ} \mathrm{C}^{-1}\right)$ and high melting point $\left(1860^{\circ} \mathrm{C}\right)$. It is one of several materials which is isomorphous with the mineral pseudobrookite $\left(\mathrm{Fe}_{2} \mathrm{TiO}_{5}\right)[1,2]$. In this structure, each $\mathrm{Al}^{3+}$ or $\mathrm{Ti}^{4+}$ cation is surrounded by six oxygen ions forming distorted oxygen octahedra. These $\mathrm{AlO}_{6}$ or $\mathrm{TiO}_{6}$ octahedra form (001) oriented double chains weakly bonded by shared edges. This structural feature is responsible for the strong thermal expansion anisotropy which generates localised internal stresses to cause severe microcracking. Although this microcracking weakens the material, it imparts a desirable low thermal expansion coefficient and an excellent thermal shock resistance.

In addition, $\mathrm{Al}_{2} \mathrm{TiO}_{5}$ is only thermodynamically stable above $1280^{\circ} \mathrm{C}$ and undergoes a eutectoid-like decomposition to $\alpha-\mathrm{Al}_{2} \mathrm{O}_{3}$ and $\mathrm{TiO}_{2}$ (rutile) within the temperature range $900-1280^{\circ} \mathrm{C}$ [3-7]. This undesirable decomposition has limited its wider application. Hitherto, the mechanisms of decomposition are poorly understood but experimental evidences suggest a nucleation and growth controlled process. It is generally agreed that the decomposition rate peaks at $1100^{\circ} \mathrm{C}$ and that residual alumina particles might act as preferred nucleation sites for the decomposition [3]. The impact of this thermal instability can be improved through the use of various stabilisers such as $\mathrm{MgO}, \mathrm{Fe}_{2} \mathrm{O}_{3}$ and $\mathrm{SiO}_{2}$.

In recent studies by Low and co-workers [8-12], both grain size and the oxygen partial pressure of the furnace atmosphere has been observed to have a profound influence on the thermal stability of $\mathrm{Al}_{2} \mathrm{TiO}_{5}$. For instance, the decomposition rate of $\mathrm{Al}_{2} \mathrm{TiO}_{5}$ at $1100^{\circ} \mathrm{C}$ is significantly enhanced in vacuum ( $10^{-4}$ torr) or argon where $>90 \%$ of $\mathrm{Al}_{2} \mathrm{TiO}_{5}$ decomposed after only $4 \mathrm{~h}$ soaking when compared to less than $10 \%$ in atmospheric air $[8,12]$. This suggests that the process of decomposition of $\mathrm{Al}_{2} \mathrm{TiO}_{5}$ is susceptible to environmental attack or sensitive to the variations in the oxygen partial pressure during ageing. The stark contrast in the mechanism of phase decomposition is believed to arise from the vast differences in the oxygen partial pressure that exists between air and vacuum.. In addition, it is still unclear whether the variation of oxygen partial pressure has any influence on the range and on-set of decomposition temperature of $\mathrm{Al}_{2} \mathrm{TiO}_{5}$.

A similar phenomenon, although less profound, has been observed for $\mathrm{Al}_{2} \mathrm{TiO}_{5}$ with a distinct difference in grain size. However, it is unclear whether there is a critical grain size associated with this phenomenon. The reason for this grain-size effect is unclear at this stage although it may be closely related to its greater tendency for microcracking as the grain size increases. The microcracking phenomenon is closely related to the material microstructure and thermal expansion anisotropy [1315]. Below a critical grain size, the elastic energy of the system is insufficient to nucleate microcracks 
during cooling and thus causing no degradation to the mechanical strength. The density of microcracks increases drastically with grain size once the critical value is exceeded.

In this paper, we present results on the effect of grain size and controlled atmospheres on the isothermal stability of $\mathrm{Al}_{2} \mathrm{TiO}_{5}$ at $1100^{\circ} \mathrm{C}$ as well as its decomposition behaviour in the temperature range $20-1400^{\circ} \mathrm{C}$. The temperature-dependent thermal stability and isothermal decomposition of $\mathrm{Al}_{2} \mathrm{TiO}_{5}$ have been dynamically monitored and characterized using neutron diffraction to study the structural changes occurring during phase decomposition in real time.

\section{EXPERIMENTAL METHODS}

\section{Sample preparation}

The starting powders used for the synthesis of $\mathrm{Al}_{2} \mathrm{TiO}_{5}$ (AT) consisted of high purity commercial alumina $\left(99.9 \% \mathrm{Al}_{2} \mathrm{O}_{3}\right)$ and rutile $\left(99.5 \% \mathrm{TiO}_{2}\right)$. One mole of alumina powder and one mole of rutile powder were initially mixed using a mortar and pestle. The powder mixture was then wet mixed in ethanol using a Turbula mixer for $2.0 \mathrm{~h}$. The slurry was then dried in a ventilated oven at $100^{\circ} \mathrm{C}$ for 24 $\mathrm{h}$. The dried powder was uniaxially-pressed in a steel die at $150 \mathrm{MPa}$ to form cylindrical bars of length $20 \mathrm{~mm}$ and diameter $15 \mathrm{~mm}$, followed by sintering in a air-ventilated furnace at (a) $1400^{\circ} \mathrm{C}$ in air for 1 $\mathrm{h}$ to achieve a fine-grained microstructure $(\sim 1-3 \mu \mathrm{m})$; (b) $1500^{\circ} \mathrm{C}$ in air for $2 \mathrm{~h}$ to achieve a mediumgrained microstructure $(\sim 5-10 \mu \mathrm{m})$, and $(c) 1600^{\circ} \mathrm{C}$ in air for $4 \mathrm{~h}$ to achieve coarse-grained $(\sim 30-50 \mu \mathrm{m})$ $\mathrm{Al}_{2} \mathrm{TiO}_{5}$.

\section{Neutron diffraction (ND)}

A medium resolution powder diffractometer (MRPD) located at the Australian Nuclear Science and Technology Organisation (ANSTO) in Lucas Heights, NSW was used for neutron diffraction study of the thermal stability of $\mathrm{Al}_{2} \mathrm{TiO}_{5}$. The effect of grain size on the isothermal stability of $\mathrm{Al}_{2} \mathrm{TiO}_{5}$ was dynamically monitored at $1100^{\circ} \mathrm{C}$ in air atmosphere for up to 12 . Medium-grained $\mathrm{Al}_{2} \mathrm{TiO}_{5}$ samples were used for the study of isothermal stability in different atmospheres, namely air, argon $199.99 \%$ purity) and $50 \%$ argon - 50\% oxygen. In addition, the influence of atmosphere on the temperature range and the onset of thermal decomposition of $\mathrm{Al}_{2} \mathrm{TiO}_{5}$ in the temperature range $20-1400^{\circ} \mathrm{C}$ was investigated. The operation conditions of the MRPD were $\lambda=1.667 \AA, 2 \theta$ range $=4-138^{\circ}$, step size $=$ $0.1^{\circ}$, counting time $\sim 40-50 \mathrm{~s} / \mathrm{step}$, monochromator of $8 \mathrm{Ge}$ crystals (115 reflection), and $32{ }^{3} \mathrm{He}$ detectors $4^{\circ}$ apart. The relative abundance of phases present was computed using the Rietveld method. The models used to calculate the phase abundance for MRPD were Maslen et al. [16] for alumina, Epicier et al. [17] for $\mathrm{Al}_{2} \mathrm{TiO}_{5}$, and Howard et al. [18] for rutile. The software used to analyse the data was Rietica 1.7.7.

\section{RESULTS AND DISCUSSION}

\section{Effect of Grain Size}

Figure 1 shows the effect of grain size on the isothermal stability of in air at $1100^{\circ} \mathrm{C}$. Coarse-grained $\mathrm{Al}_{2} \mathrm{TiO}_{5}$ exhibits a slowest rate of thermal decomposition when compared to its medium-grained and fine-grained counterparts. To the best of our knowledge, this is the first time that grain size has been shown to affect the propensity of thermal degradation in $\mathrm{Al}_{2} \mathrm{TiO}_{5}$. However, it is unclear whether there is a critical grain size associated with this phenomenon. The reason for this grain-size effect is unclear at this stage although it may be closely related to its greater tendency for microcracking as the grain size increases. The microcracking phenomenon is closely related to the material microstructure and thermal expansion anisotropy [13-15]. Below a critical grain size, the elastic energy of the system is insufficient to nucleate microcracks during cooling and thus causing no degradation to the mechanical strength. The density of microcracks increases drastically with grain size once the critical value is exceeded.

Fig. 2(a) shows the typical microstructure of as-sintered coarse-grained AT prior to isothermal ageing where the presence of fine microcracks within certain grains is clearly evident. The formation of these microcracks can be attributed to the pronounced thermal expansion anisotropy of AT during cooling from an elevated temperature. The presence of these microcracks is believed to impart a low fracture strength but high thermal shock resistance to AT. Following isothermal-ageing in air at $1000^{\circ} \mathrm{C}$ for $14 \mathrm{~h}$, both needle-like and angular particles could be seen to form on the surface of $\mathrm{Al}_{2} \mathrm{TiO}_{5}$ grains [19]. Based on the energy dispersive spectrocopy (EDS) results [19], these nano-sized particles were identified as surface by-products (ie. $\mathrm{Al}_{2} \mathrm{O}_{3}$ and $\mathrm{TiO}_{2}$ ) of thermally decomposed AT. This may indicate 
that the initial nucleation process of thermal decomposition of AT is surface-initiated and the growth kinetics are both temperature and time dependent.

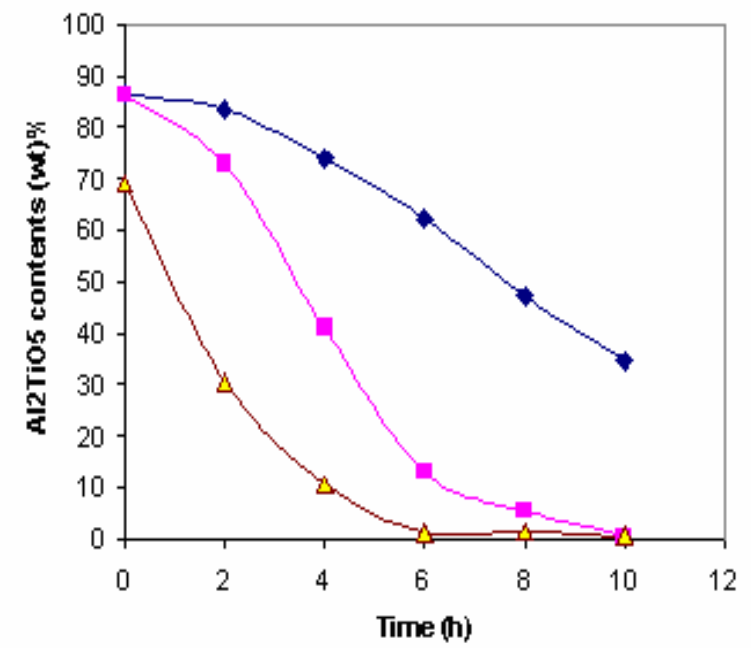

Fig. 1: Effect of $\mathrm{Al}_{2} \mathrm{TiO}_{5}$ grain size on the propensity of isothermal decomposition at $1100^{\circ} \mathrm{C}$ in air.

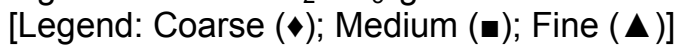

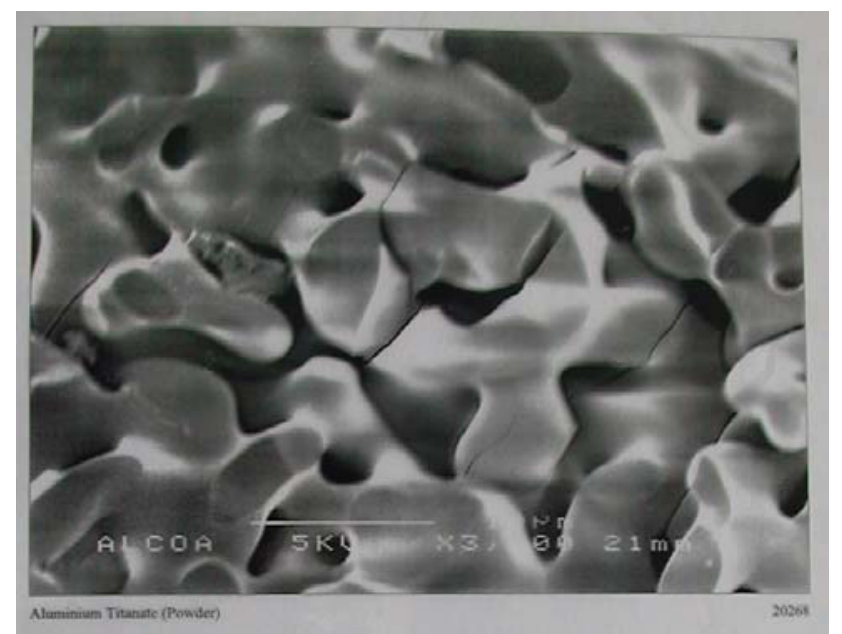

Fig.2: Scanning electron micrograph of as-sintered medium-grained AT. Note the presence of microcracks within certain grains.

\section{Effect of Controlled Atmospheres}

Figure 3 shows the isothermal stability of $\mathrm{Al}_{2} \mathrm{TiO}_{5}$ at $1100^{\circ} \mathrm{C}$ in air for $12 \mathrm{~h}$ duration. The sample remained fairly stable with no apparent phase decomposition for up to $5 \mathrm{~h}$. Further ageing caused only $\sim 5 \%$ decomposition. In contrast, substantial phase decomposition was observed when $\mathrm{Al}_{2} \mathrm{TiO}_{5}$ was aged in an argon atmosphere (Fig. 4) where more than $98 \%$ of the sample decomposed to form corundum $\left(\mathrm{Al}_{2} \mathrm{O}_{3}\right)$ and rutile $\left(\mathrm{TiO}_{2}\right)$ after only $5 \mathrm{~h}$ of ageing. When the ageing atmosphere was changed to $50 \%$ argon and $50 \%$ oxygen (Fig. 5), the decomposition rate was considerably reduced compared with the rate for $100 \%$ argon but more substantial than the rate for air.

A closer look at the results in Figs. 3-5 suggests that the propensity of phase decomposition of $\mathrm{Al}_{2} \mathrm{TiO}_{5}$ is dependent on the atmosphere or oxygen partial pressure during isothermal ageing. This implies that the oxygen partial pressure in the atmosphere plays a key role in triggering the thermal instability via oxygen nonstoichiometry changes and/or disordering of cations in $\mathrm{Al}_{2} \mathrm{TiO}_{5}$ [6]. Indeed, nitrogen atmosphere has also been observed to cause enhanced thermal instability in $\mathrm{Al}_{2} \mathrm{TiO}_{5}[20]$. 
Similar observations have also been observed for the enhanced dissociation of $\mathrm{Ti}_{3} \mathrm{SiC}_{2}$ in vacuum and argon which can also be attributed to the role of oxygen partial-pressures [21,22].

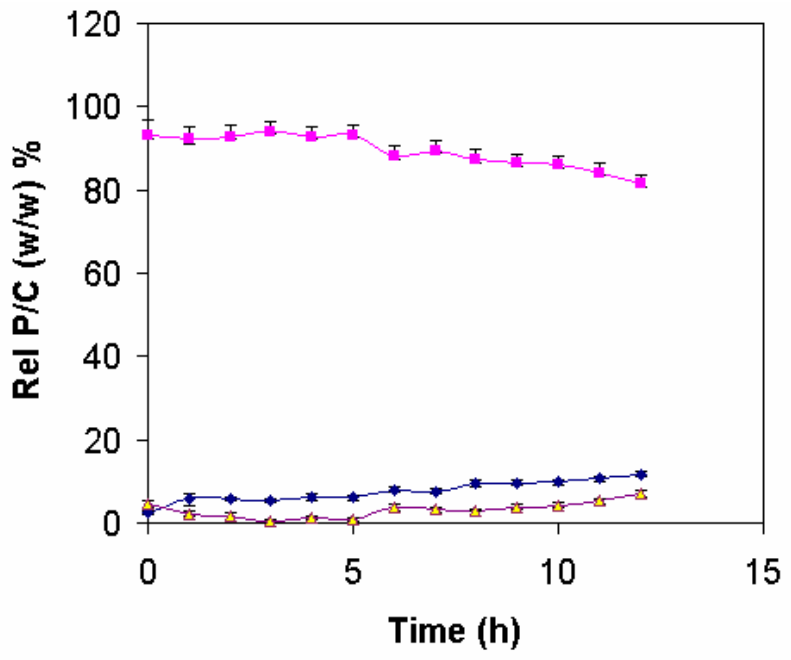

Fig. 3: Isothermal stability of $\mathrm{Al}_{2} \mathrm{TiO}_{5}$ at $1100^{\circ} \mathrm{C}$ in air. Errors bars indicate two estimated standard deviations $\pm 2 \sigma$. [Legend: $\|=\mathrm{Al}_{2} \mathrm{TiO}_{5} ;-=\mathrm{Al}_{2} \mathrm{O}_{3} ; \Delta=\mathrm{TiO}_{2}$ ]

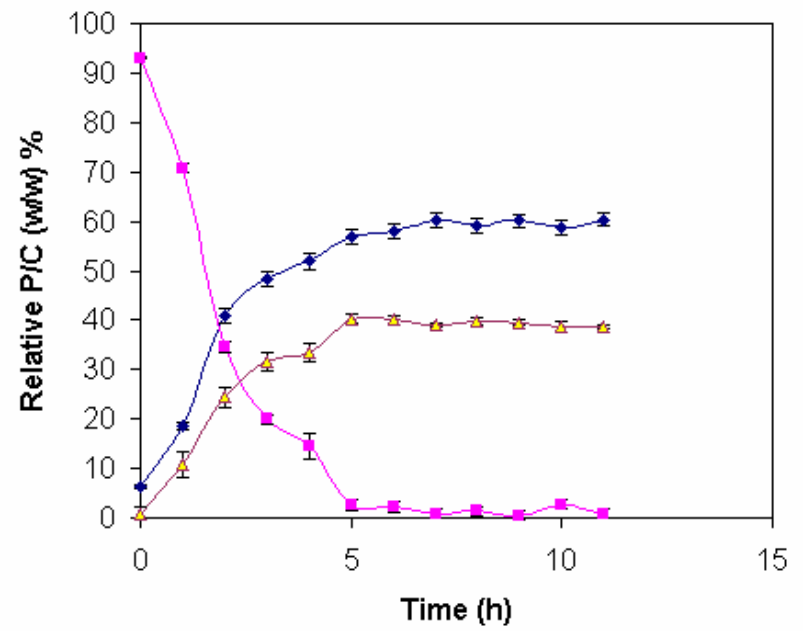

Fig. 4: Isothermal stability of $\mathrm{Al}_{2} \mathrm{TiO}_{5}$ at $1100^{\circ} \mathrm{C}$ in controlled argon atmosphere. Errors bars indicate two estimated standard deviations $\pm 2 \sigma$. [Legend: $\bullet=\mathrm{Al}_{2} \mathrm{TiO}_{5} ; \bullet=\mathrm{Al}_{2} \mathrm{O}_{3} ; \Delta=\mathrm{TiO}_{2}$ ]

It is postulated that in the presence of very low oxygen partial pressure, the titanium ions in $\mathrm{TiO}_{2}$ are very susceptible to non-stoichiometry, thus triggering the release of oxygen atoms and the concomitant decomposition process. However, the exact mechanism of enhanced phase decomposition in argon or inert atmosphere remains unclear, especially in relation to the role of oxygen partial pressures in reducing the free energy change for thermal decomposition of $\mathrm{Al}_{2} \mathrm{TiO}_{5}$. If the oxygen partial pressure is the cause, then the decomposition rate of $\mathrm{Al}_{2} \mathrm{TiO}_{5}$ should depend on the variation of the oxygen partial pressure as indicated in Figs. 3 - 5. It follows that an increase in the oxygen partial pressure should reduce the rate of decomposition and vice-versa. This further implies that the thermal stability of $\mathrm{Al}_{2} \mathrm{TiO}_{5}$ will be improved in an atmosphere of $100 \%$ oxygen when compared to ageing in air.

The thermal stability of $\mathrm{Al}_{2} \mathrm{TiO}_{5}$ in the temperature range $20-1400^{\circ} \mathrm{C}$ in argon is shown in Fig. 6 . Clearly, $\mathrm{Al}_{2} \mathrm{TiO}_{5}$ was stable up to $\sim 1100^{\circ} \mathrm{C}$ and became unstable at between $\sim 1150-1300^{\circ} \mathrm{C}$. Beyond $1300^{\circ} \mathrm{C}$, the thermal decomposition was arrested and the phase stability was restored. This implies that the process of thermal decomposition is reversible or recoverable provided the restricted temperature range of between $\sim 1150-1300^{\circ} \mathrm{C}$ is not transgressed. The implication of this phenomenon is far-reaching whereby it may be possible to restore the decomposed $\mathrm{Al}_{2} \mathrm{TiO}_{5}$ to its 
original condition by thermal annealing at $>1400^{\circ} \mathrm{C}$. Interestingly, the use of either air, argon or oxygen atmosphere did not appear to alter the on-set temperature and the temperature range of thermal decomposition, although the propensity of phase decomposition was dramatically affected [8]. The reason for this phenomenon is unclear at this stage. To the best of our knowledge, this is the first time that the in-situ display of the temperature range for thermal decomposition of $\mathrm{Al}_{2} \mathrm{TiO}_{5}$ during ageing in controlled atmospheres as shown in Fig. 5 has been reported in the literature.

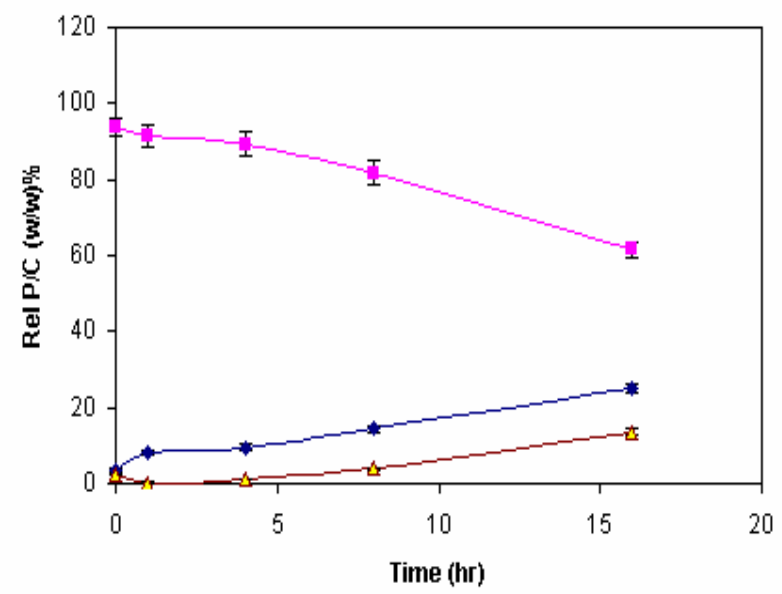

Fig. 5: Isothermal stability of $\mathrm{Al}_{2} \mathrm{TiO}_{5}$ at $1100^{\circ} \mathrm{C}$ in the controlled atmosphere of $50 \%$ oxygen and $50 \%$ argon. Errors bars indicate two estimated standard deviations $\pm 2 \sigma$. [Legend: $=\mathrm{Al}_{2} \mathrm{TiO}_{5} ;=\mathrm{Al}_{2} \mathrm{O}_{3} ; \Delta$ $\left.=\mathrm{TiO}_{2}\right]$

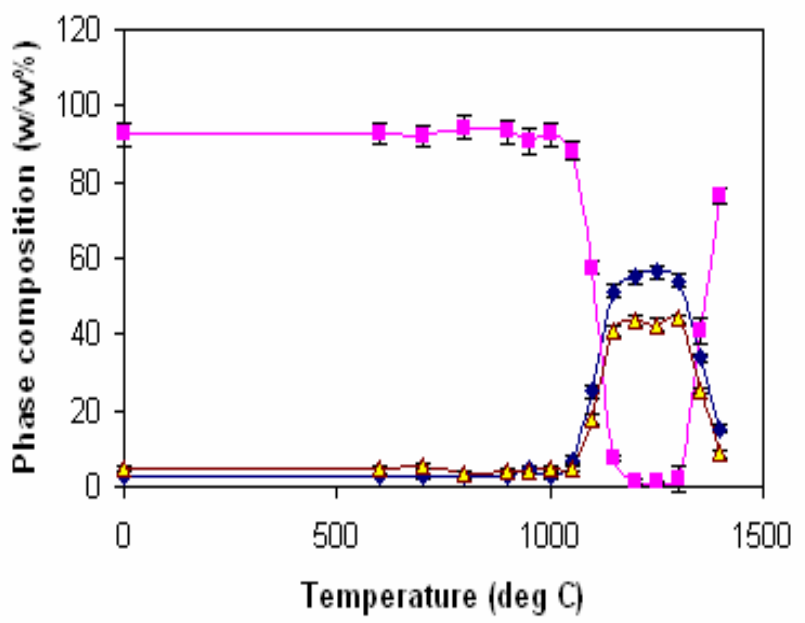

Fig. 6: Thermal stability of $\mathrm{Al}_{2} \mathrm{TiO}_{5}$ in controlled argon atmosphere over the temperature range 20 $1400^{\circ} \mathrm{C}$. Note the display of pronounced thermal decomposition at $\sim 1150-1300^{\circ} \mathrm{C}$. Errors bars indicate two estimated standard deviations $\pm 2 \sigma$. [Legend: $=\mathrm{Al}_{2} \mathrm{TiO}_{5} ;=\mathrm{Al}_{2} \mathrm{O}_{3} ; \Delta=\mathrm{TiO}_{2}$ ]

\section{CONCLUSION}

The effects of grain size and controlled furnace atmospheres on the thermal stability of $\mathrm{Al}_{2} \mathrm{TiO}_{5}$ at $1100^{\circ} \mathrm{C}$ and in the temperature range $20-1400^{\circ} \mathrm{C}$ have been dynamically examined by neutron diffraction. The thermal stability of $\mathrm{Al}_{2} \mathrm{TiO}_{5}$ increases as the grain size and oxygen partial pressure increases. The susceptibility of $\mathrm{Al}_{2} \mathrm{TiO}_{5}$ to thermal decomposition increases as the oxygen partial pressure of the furnace atmosphere decreases. However, neither the on-set temperature nor the temperature range of thermal decomposition is affected by the variation of oxygen partial pressure present in controlled furnace atmospheres. 


\section{ACKNOWLEDGMENTS}

This work was supported by funding from the Australian Institute of Nuclear Science and Engineering (AINSE Awards 04/207 \& 05/206). We are grateful to our colleague, E/Prof. B. O'Connor, for advice on Rietveld analysis of XRD data. We thank Mr. M. Prior of the Bragg Institute of ANSTO for experimental assistance in the collection of MRPD data. We also thank Mr. A. Jones of Alcoa for assistance in SEM work.

\section{REFERENCES}

1. A.E. Austin and C.M. Schwartz, Acta Cryst. 6, 812 (1953).

2. B. Morosin and R.W. Lynch, Acta Cryst. B. 28, 1040 (1972).

3. H.A.J. Thomas and R. Stevens, Br. Ceram Trans. J. 88, 144 (1989).

4. G. Tilloca, J. Mater. Sci. 26, 2809 (1991).

5. E., Kato, K. Daimon and Y. Kobayashi, J. Am. Ceram. Soc. 63, 355 (1980).

6. R.W. Grimes and J. Pilling, J. Mater. Sci. 29, 2245 (1994).

7. M. Ishitsuka, et al., J. Am. Ceram. Soc. 70, 69 (1987).

8. I.M. Low, D. Lawrence and R.I. Smith, J. Am. Ceram. Soc. 88, 2957 (2005).

9. I.M. Low, P. Manurung, R.I. Smith and D. Lawrence, Key Eng. Mater. 224-226, 465 (2002).

10. I.M. Low, Z. Oo \& B. O'Connor, Physica B. 385-386, 502 (2006).

11. I.M. Low and R.I. Smith, pp.175-176 in Proc. of AUSTCERAM 2002 (Eds. I.M. Low \& D.N. Phillips), 30 Sept - 4 Oct. 2002, Perth, WA.

12. I.M. Low, D. Lawrence, A. Jones and R.I. Smith, $29^{\text {th }}$ Int. Cocoa Beach Conference on Advanced Ceramics \& Composites: (D. Zhu \& W.M. Kriven, Eds.) CESP. Vol. 26, Issue 3 \& 4, pp. 303-310 (2005).

13. K. Hamano, Y. Ohya and Z. Nakagawa, pp. 129-137 in Int. Journal of High Tech. Ceram. Elsevier Science Publishers Ltd., UK. (1985).

14. Y. Ohya, Z. Nakagawa and K. Hamano, J. Am. Ceram. Soc. 71, C23 (1988).

15. Y. Ohya and Z. Nakagawa, J. Am. Ceram. Soc. 70, C184 (1987).

16. E.N. Maslen, V.A. Streltsov, N.R. Streltsova, N. Ishizawa and Y. Satow, Acta Cryst. B. 49, 937 (1993).

17. T. Epicier, G. Thomas, H. Wohlfromm and J.S. Moya, J. Mater. Res. 6, 138 (1991).

18. C.J. Howard, T.M. Sabine and F. Dickson, Acta Cryst. B. 47, 462 (1991).

19. A. Jones and I.M. Low, pp.185-186 in Proc. of AUSTCERAM 2002 (Eds. I.M. Low \& D.N. Phillips), 30 Sept -4 Oct. 2002, Perth, WA.

20. D.S. Perera and M.E. Bowden, J. Mater. Sci. 26, 1585 (1991).

21. Z. Oo, I.M. Low and B.H. O'Connor, Physica B. 385-386, (2006) 499-501.

22. I.M Low, Mater. Lett. 58, 927 (2004). 